\title{
Quadriceps muscle strength in scoliosis
}

\author{
E.B. Swallow*, E. Barreiro", H. Gosker", S.A. Sathyapala*, F. Sanchez", \\ N.S. Hopkinson*, J. Moxham ${ }^{+}$, A. Schols ${ }^{\star}$, J. Gea* and M.I. Polkey*, on behalf of the \\ ENIGMA in COPD project
}

ABSTRACT: Quadriceps muscle weakness is an important component of chronic obstructive pulmonary disease (COPD). We hypothesised that quadriceps weakness would also be a feature of restrictive lung disease due to scoliosis.

We studied 10 patients with severe scoliosis (median (interquartile range (IQR)) forced expiratory volume in $1 \mathrm{~s}$ (FEV1) 35.3 (11)\% predicted), 10 patients with severe COPD (FEV 126.5 (9.0)\% pred) and 10 healthy age-matched adults. We measured quadriceps strength, exercise capacity and analysed quadriceps muscle biopsies for myosin heavy-chain (MyHC) isoform expression and the presence of oxidative stress.

Both groups exhibited quadriceps weakness with median (IQR) maximal voluntary contraction force being $46.0(17.0) \mathrm{kg}, 21.5(21.0) \mathrm{kg}$ and $31.5(11.0) \mathrm{kg}$, respectively $(p=0.02$ and 0.04 , respectively, for each patient group against controls). Oxidative stress was significantly greater in the quadriceps of both restrictive and COPD patients. The scoliosis patients exhibited a decrease in the proportion of MyHC type I compared with controls; median (IQR) 35.3 (18.5)\% compared with $47.7(9.3) \%, p=0.028$. The scoliosis patients also showed an increase in MyHC IIx (26.3 (15.5)\% compared with $11.3(13.0) \%, p=0.01$.

Quadriceps weakness is a feature of severe scoliosis; the similarities between patients with scoliosis and patients with COPD suggest a common aetiology to quadriceps weakness in both conditions.

KEYWORDS: Chronic obstructive pulmonary disease, extrapulmonary restrictive lung disease, oxidative stress, quadriceps muscle weakness

n patients with advanced chronic obstructive pulmonary disease (COPD), quadriceps wasting and weakness are both features which suggest a poor prognosis [1, 2], but few data exist concerning quadriceps weakness in other chronic pulmonary diseases and, to our knowledge, none on the underlying muscle phenotype and molecular changes. Although pulmonary rehabilitation (PR) is of benefit in both patients with restrictive lung disease [3] and COPD [4], most investigators agree that precise understanding of the causes of quadriceps weakness in pulmonary disease might allow the development of therapies that could be offered to patients as an adjunct to PR or to patients who are unable to participate in PR.

In addition to weakness, several biopsy-based observations are recognised as components of the COPD quadriceps phenotype. These include oxidative stress [5] along with a fibre type switch to a less resistant phenotype [6]. Since scoliosis, like COPD, when severe causes exercise limitation and respiratory failure, we considered that we might also observe quadriceps weakness in patients with scoliosis and that they might exhibit a peripheral muscle phenotype which resembled that of patients with COPD.

\section{METHODS}

\section{Subjects}

10 patients with idiopathic scoliosis and 10 patients with severe COPD were recruited from the home ventilation and advanced emphysema clinics at the Royal Brompton Hospital (Imperial College, London, UK). The scoliotic patients had been referred for assessment of symptoms that might be attributable to nocturnal hypoventilation in the presence of reduced spirometry. COPD patients had been referred for this purpose or for consideration of lung volume reduction surgery or lung transplantation. Subjects were stable at the time of the study and were on standard treatment for their lung disease, including, where appropriate,
AFFILIATIONS

*Muscle Laboratory, Royal Brompton Hospital \& NHLI, Imperial College, and

${ }^{+}$Respiratory Muscle Laboratory, Kings College Hospital, London, UK "Muscle and Respiratory System Research Unit, Respiratory Medicine Dept, IMIM - Hospital del Mar. CIBER de Enfermedades Respiratorias (CIBERES), ISCiii, Spanish Ministry of Health. Dept CEXS, Universitat Pompeu Fabra (UPF), Barcelona, Spain. 'Dept of Pulmonology, University of Maastricht, Maastricht, The Netherlands.

CORRESPONDENCE

M.I. Polkey

Respiratory Muscle Laboratory

Royal Brompton Hospital

Fulham

Road

London

SW3 6NP

UK

E-mail: m.polkey@rbht.nhs.uk

Received:

May 152008

Accepted after revision:

April 282009

First published online:

May 142009 
bronchodilators and inhaled corticosteroids, but not noninvasive ventilation, which was the reason for referral. No patients were on long-term oral steroids. Two of the COPD patients had received short courses of oral prednisolone as treatment for exacerbation: most recently, one patient had received prednisolone 4 months and the other 5 months prior to being studied. Exclusion criteria included cardiovascular disease, chronic metabolic diseases, suspected para-neoplastic or myopathic syndromes, and/or treatment with drugs known to alter muscle structure and/or function. Five patients in the COPD group were on long-term domiciliary oxygen as opposed to one in the scoliosis group. 10 healthy age-matched control subjects recruited from a register in our laboratory were also studied. The Royal Brompton Hospital Research Ethics Committee approved the study and all subjects provided written, informed consent.

\section{Nutritional and physiological measurements}

Anthropometric measurements, fat-free mass determined by bioelectrical impedance analysis [7] and pulmonary function tests were recorded in both patients and controls. Patients in the restrictive group had their arm span distance used instead of height since it was greater [8]. The patient groups also completed a 6-min walk test (6MWT) repeated on two occasions; the highest result obtained was used for analysis.

\section{Quadriceps force measurements}

Subjects were studied supine, with the knee flexed at $90^{\circ}$ over the end of the bed, in a modification of the method of EDWARDS et al. [9]; the dominant leg was studied and signals recorded using apparatus previously described [10]. Quadriceps strength was measured by supramaximal magnetic stimulation of the femoral nerve (quadriceps twitch force (TwQ)) and by maximal isometric voluntary contraction (quadriceps maximal voluntary contraction (QMVC)) following a 20-min rest period for depotentiation [11]. Femoral nerve stimulation [12] was performed with a double Magstim 200 magnetic stimulator (Magstim Co., Dyfed, UK) discharging both units simultaneously through a 70-mm "branding iron" coil. The optimal coil position was determined at the start of the experiment; supramaximality was confirmed in each subject by recording the unpotentiated TwQ at a range of stimulus intensities between 70 and 100\% output. A minimum of seven stimuli at $100 \%$ were then performed and TwQ defined as the mean of these recordings. QMVC was performed so that the force generated was visible to subject and investigator for positive feedback. Efforts were sustained for $\geqslant 5 \mathrm{~s}$. Subjects rested for $30 \mathrm{~s}$ between each contraction to minimise "twitch-on-twitch" potentiation [13]. A minimum of three efforts was made with vigorous encouragement until there was no improvement in performance; the biggest effort recorded was used for analysis.

\section{Quadriceps muscle biopsy}

A needle biopsy of the vastus lateralis of the contralateral (i.e. non-dominant) leg was performed in all subjects [14]. The samples were immediately frozen in liquid nitrogen and stored at $-80^{\circ} \mathrm{C}$ until further processing.

\section{Muscle biopsy analyses}

Full details may be found in the supplementary material available online but, in brief, we performed analysis for myosin heavy-chain (MyHC) isoform expression at the University of Maastricht (Maastricht, the Netherlands) using previously described methods [15]. We also sought evidence of oxidative stress in muscle proteins and lipids in Barcelona using previously described methods $[5,16,17]$.

\section{Statistical analysis}

Data are expressed as median \pm interquartile range unless otherwise stated. Differences between the three groups were explored using the Kruskal-Wallis test followed by the MannWhitney test since it could not be safely assumed that the data were normally distributed. A p-value of $<0.05$ was taken to be significant. A statistical software package was used for all calculations (Statview; SAS Institute, Cary, NC, USA).

\section{RESULTS}

\section{Characteristics of the study subjects}

The characteristics of the subjects are shown in table 1 . The patient and control groups were well matched with respect to age. Fat-free mass index did not differ between groups but the body mass index (BMI) was reduced in scoliotic patients compared with both controls and COPD patients $(p=0.03$ for both). There was significant but comparable lung function abnormality, judged by forced expiratory volume in $1 \mathrm{~s}$ (FEV1), in both patient groups with a median (IQR) FEV1 of $35.3(11) \%$ predicted for the scoliotic patients and a severe obstructive defect in the COPD group (FEV1 26.5 (9.0)\% pred).

\begin{tabular}{|c|c|c|c|}
\hline & $\begin{array}{l}\text { Control } \\
\text { group }\end{array}$ & $\begin{array}{c}\text { Scoliosis } \\
\text { group }\end{array}$ & $\begin{array}{l}\text { COPD } \\
\text { group }\end{array}$ \\
\hline Subjects n & 10 & 10 & 10 \\
\hline Males $\mathbf{n}$ & 10 & 3 & 10 \\
\hline Age yrs & $61(13)$ & $63.5(6.0)$ & $65.0(13.0)$ \\
\hline Height/arm span m & $1.76(0.9)$ & $1.62(0.34)^{*, \#}$ & $1.75(0.6)$ \\
\hline Weight kg & $81.1(13.8)$ & $57.9(27.7)^{\star, \#}$ & $86.3(24.4)$ \\
\hline BMI $\mathbf{k g} \cdot \mathrm{m}^{-2}$ & $26.0(4.0)$ & $22.4(9.1)^{*, \#}$ & $27.6(5.9)$ \\
\hline FFMI $\mathrm{kg} \cdot \mathrm{m}^{-2}$ & $18.0(2.3)$ & $14.9(7.5)$ & $17.7(1.9)$ \\
\hline FEV $1 \%$ pred & $89.5(33.0)$ & $35.3(11.0)^{*}$ & $26.5(9.0)^{*}$ \\
\hline FVC \% pred & $90.0(20.0)$ & $44.0(22.0)^{\star}$ & $73.0(20.0)^{\star}$ \\
\hline FEV $_{1} /$ FVC & $83.0(15.0)$ & $80.1(15.2)$ & $31.4(16.6)^{*}$ \\
\hline $\mathrm{Pa}, \mathrm{O}_{2} \mathrm{kPa}$ & & $9.1(1.13)$ & $7.49(1.71)$ \\
\hline $\mathrm{Pa}, \mathrm{CO}_{2} \mathrm{kPa}$ & & $5.73(1.29)$ & $6.64(0.88)$ \\
\hline 6MWD m & & 300 (199) & $155(180)$ \\
\hline QMVC kg & $46.0(17.0)$ & $21.5(21.0)^{*}$ & $31.5(11.0)^{*}$ \\
\hline QMVC as \% of BMI & $172(48.4)$ & $106(33.0)^{*}$ & $115(21.1)^{*}$ \\
\hline TwQ kg & $9.65(3.0)$ & $5.9(3.3)^{\star}$ & $6.5(4.3)$ \\
\hline
\end{tabular}

Data are presented as median (interquartile range), unless otherwise stated COPD: chronic obstructive pulmonary disease; BMI: body mass index; FFMI: fat-free mass index; FEV1: forced expiratory volume in $1 \mathrm{~s} ; \%$ pred: \% predicted; FVC: functional vital capacity; $\mathrm{Pa}, \mathrm{O}_{2}$ : arterial oxygen tension; $\mathrm{Pa}_{1} \mathrm{CO}_{2}$ : arterial carbon dioxide tension; 6MWD: 6-min walk distance; QMVC: quadriceps maximal voluntary contraction; TwQ: quadriceps twitch force. *: $p<0.05$ or smaller between patient group and control group; *: $p<0.05$ or smaller between restrictive and COPD group. 

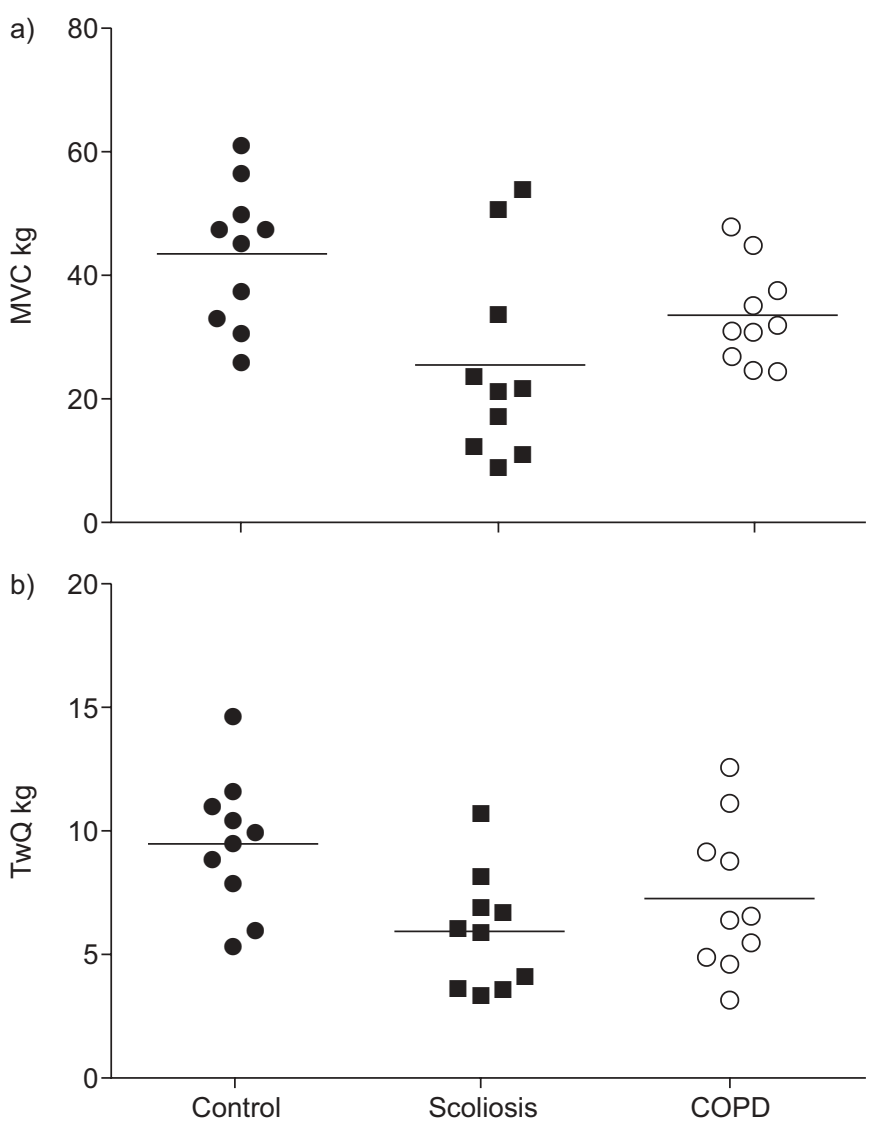

FIGURE 1. Quadriceps strength in the three patient groups measured as a) maximal voluntary contraction (MVC) force and b) unpotentiated quadriceps twitch tension (TwQ). Quadriceps strength was reduced in both scoliosis and chronic obstructive pulmonary disease (COPD) patients compared with controls judged by MVC ( $p=0.02$ and $p=0.04$, respectively) and, in the case of restrictive patients, by TwQ $(p=0.013)$.

As expected, the restrictive patients had a high ratio of FEV1/ functional vital capacity (0.80) and the COPD patients had a low ratio (0.31) (table 1). All participants were nonsmokers, with the exception of one scoliotic and one COPD patient; all the COPD patients had been smokers, as had three other scoliotic patients and seven of the controls.

\section{Quadriceps force measurement}

Quadriceps strength differed significantly between groups judged by the Kruskal-Wallis test when assessed using either twitch force $(\mathrm{p}=0.03)$ or maximal voluntary contraction (MVC; $\mathrm{p}=0.05$ ) (fig. 1). Direct group comparisons showed that the scoliotic patients were not statistically different from the COPD group (table 1), but quadriceps strength was also reduced in both scoliosis and COPD patients compared with controls judged by MVC ( $p=0.02$ and $p=0.04$, respectively) and, in the case of restrictive patients, by TwQ $(p=0.013)$.

\section{Muscle biological analyses}

Results corresponding to $\mathrm{MyHC}$ isoform expression, oxidative and redox balance are shown in table 2. Analysis of MyHCs showed significant differences in the proportions of Type IIa $(\mathrm{p}=0.011)$, Type IIx $(\mathrm{p}=0.03)$ and Type I $(\mathrm{p}=0.001)$ myosin,

\begin{tabular}{lccc} 
TABLE 2 & Muscle biopsy data & & \\
& $\begin{array}{c}\text { Control } \\
\text { group }\end{array}$ & $\begin{array}{c}\text { Restrictive } \\
\text { group }\end{array}$ & $\begin{array}{c}\text { COPD } \\
\text { group }\end{array}$ \\
\hline MyHC I \% & $47.7(9.3)$ & $35.3(18.5)^{*}$ *\# & $22.1(16.3)^{*}$ \\
MyHC IIA \% & $37.0(3.5)$ & $37.4(12.8)^{\#}$ & $50.8(10.0)^{*}$ \\
MyHC IIX \% & $11.3(13.0)$ & $26.3(15.5)^{*}$ & $24.8(13.4)$ \\
Total protein carbonylation & $3.82(1.14)$ & $5.71(2.71)^{*}$ & $4.08(0.55)$ \\
MDA-protein adducts & $0.46(0.22)$ & $1.02(2.63)^{*}$ & $1.35(0.58)^{*}$ \\
Protein tyrosine nitration & $0.24(0.06)$ & $0.76(0.51)^{*}$ & $0.48(0.30)^{*}$ \\
Mn-SOD & $0.70(0.21)$ & $0.96(0.351)^{\#}$ & $0.50(0.165)$ \\
Catalase & $1.32(0.49)$ & $1.54(0.45)$ & $1.34(0.24)$
\end{tabular}

Data are presented as median (interquartile range). Optical densities of the oxidative stress markers in all cases were expressed as the ratio of the optical densities of the specific antigen to those of glyceraldehyde-3-phosphate dehydrogenase. The number of subjects for which biopsy data are available may be obtained by examination of figures 2 and 3. COPD: chronic obstructive pulmonary disease; MyHC: myosin heavy-chain isoform; MDA: malondialdehyde; Mn-SOD: manganese superoxide dismutase. *: $p<0.05$ or smaller between patient group and control group; ${ }^{*}: \mathrm{p}<0.05$ or smaller between restrictive and COPD groups

explained by a significant difference in the proportions of Type I and IIa myosins between healthy subjects and COPD patients $(p=0.009$ and $p=0.0009$, respectively) and by significant differences between the scoliosis patients and controls (Type I myosin $\mathrm{p}=0.028$, Type IIx $\mathrm{p}=0.01$ ). Overall, the scoliosis group had a similar MyHC Type I profile to the COPD group (fig. 2).

The oxidative stress markers malondialdehyde (MDA)-protein adducts (figs 3 and 4), protein tyrosine nitration (figs 3 and 5) and protein carbonylation differed significantly between groups $(\mathrm{p}=0.001, \mathrm{p}=0.001$ and $\mathrm{p}=0.05$, respectively). These differences were explained by a significant increase in the quadriceps of scoliosis patients in MDA-protein adducts $(p=0.002)$, protein tyrosine nitration $(p=0.001)$ and protein carbonylation $(p=0.04)$. Statistically significant increases in two of these variables were also observed in COPD patients (MDA-protein adducts and protein tyrosine nitration, $\mathrm{p}=0.002$ and $p=0.008$, respectively). The antioxidant mechanism manganese superoxide dismutase but not catalase differed between the three groups (table 2) and was increased in scoliotic patients compared with COPD patients $(\mathrm{p}=0.01)$.

Indices of oxidative stress were compared with physiological data. No significant responses were observed, except a modest negative relationship observed between quadriceps strength measured as maximal voluntary contraction force and protein tyrosine nitration $(\rho=-0.46, p=0.027)$.

\section{DISCUSSION}

The main finding of the present study is that patients with very severe scoliosis display marked quadriceps weakness with a reduction in exercise performance, judged by the $6 \mathrm{MWT}$, to approximately two-thirds of expected values. In addition to a comparable degree of weakness, we observed, based on muscle biopsy data, strong similarities between scoliotic 

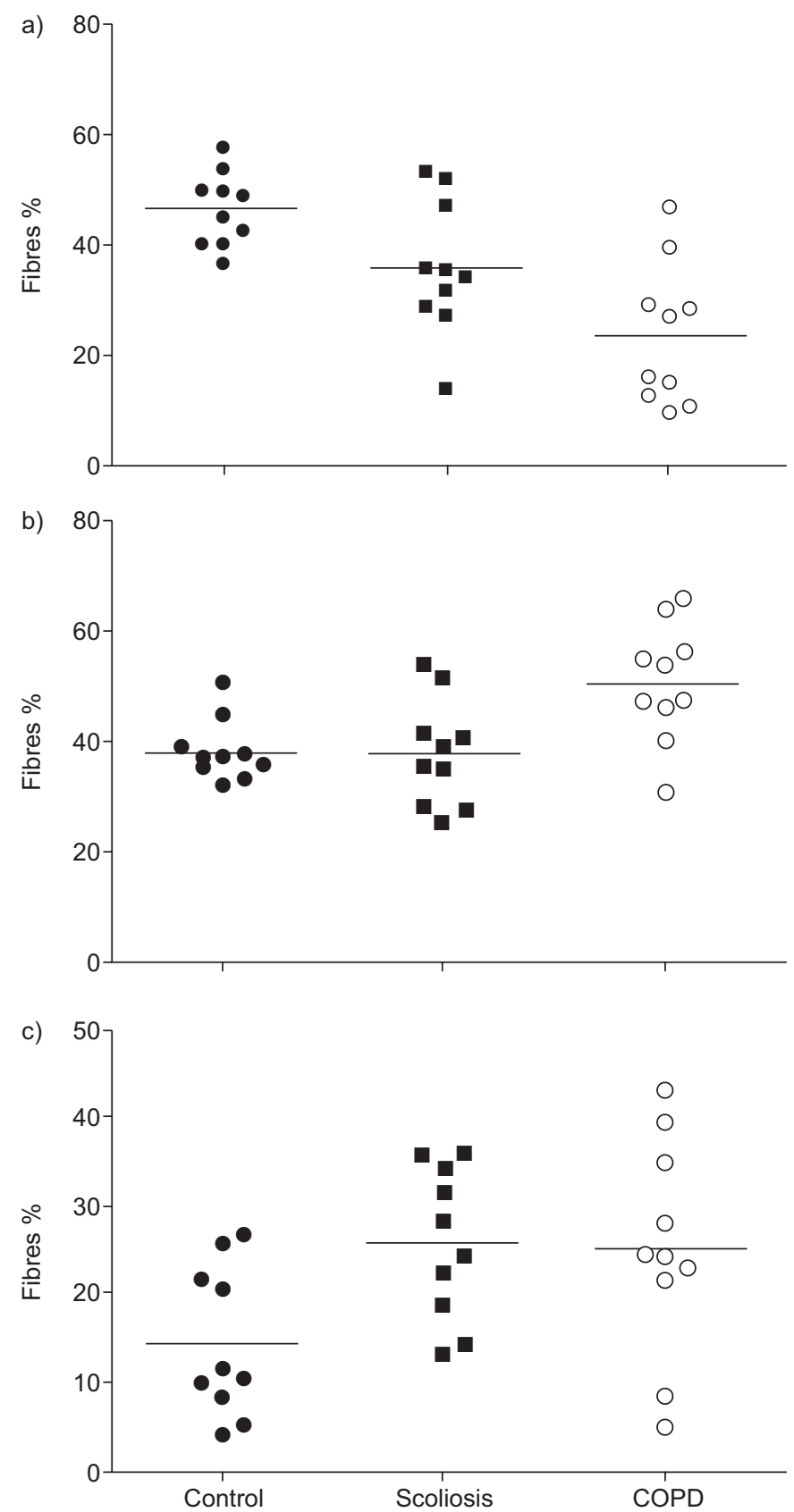

FIGURE 2. Myosin heavy-chain (MyHC) expression in the following three groups is shown: a) Type 1; b) Type Ila; and c) Type Ilx. Scoliosis patients differed from controls in Type I MyHC isoform expression, $p=0.028$ and Type $\| x p=0.01$. Chronic obstructive pulmonary disease (COPD) patients differed from controls in expression of Type I and Ila myosins ( $p=0.009$ and $p=0.0009$, respectively).

patients and COPD patients; both groups had a reduction in Type I myosin and evidence of oxidative stress suggesting a common aetiological mechanism.

\section{Critique of the method}

To some extent, the present study is exploratory in nature and therefore has some limitations. Some investigators have hypothesised that COPD is a specific inflammatory disorder triggered and modulated by tobacco smoking and that the quadriceps weakness follows downstream from this inflammation (e.g. [18]).
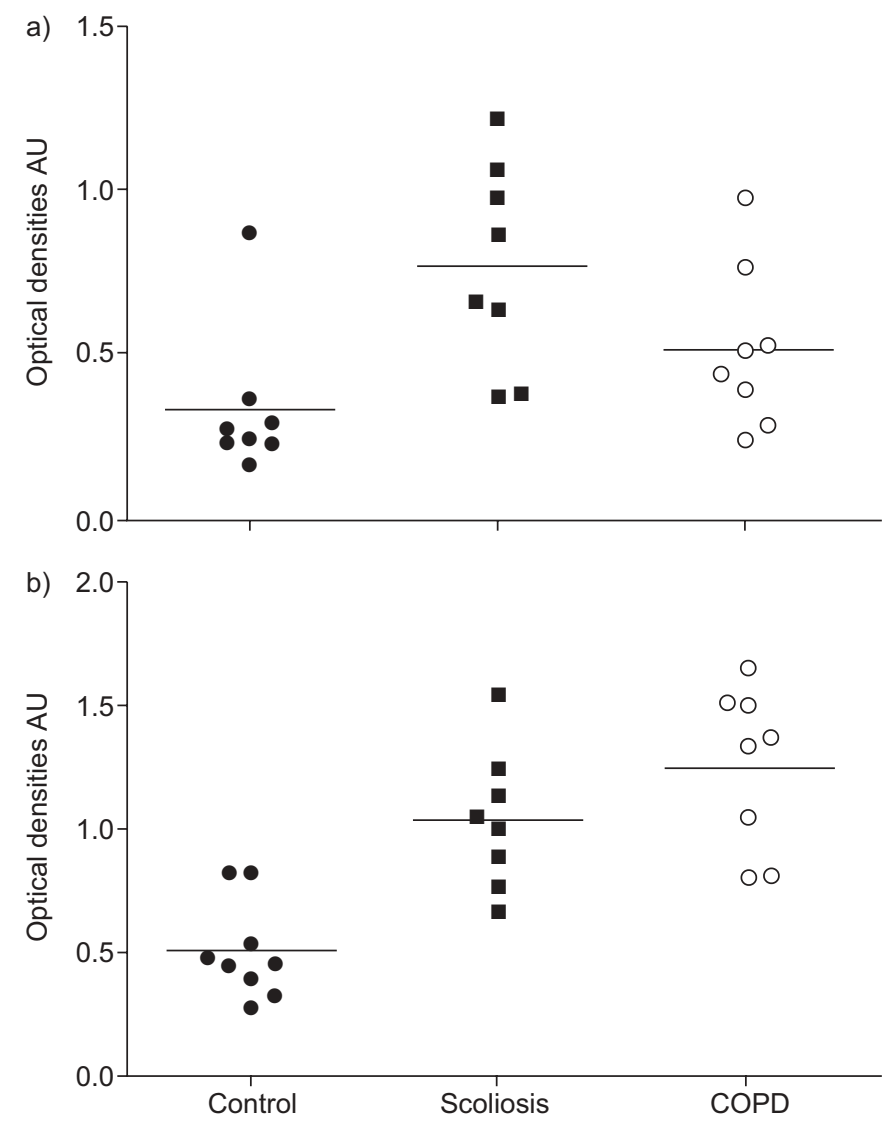

FIGURE 3. a) Protein tyrosine nitration and b) malondialdehyde (MDA)-protein adducts in all three groups. In scoliosis patients, MDA-protein adducts $(p=0.002)$ and protein tyrosine nitration $(p=0.001)$ were both increased. These variables were also increased in chronic obstructive pulmonary disease (COPD) patients ( $p=0.002$ and $p=0.008$, respectively) compared to control subjects.

If that were the case, then quadriceps weakness would not, of necessity, be present in noninflammatory respiratory conditions such as scoliosis. Although our data, in this context, argue against an inflammatory aetiology to peripheral muscle weakness in COPD, we acknowledge that blood markers of inflammation, such as interleukin (IL)- 6 , IL- 8 or tumour necrosis factor- $\alpha$, were not measured in the present study. Interestingly, our consortium [19] and others [20] have recently demonstrated that these inflammatory markers are in any case under- rather than overrepresented in the limb muscle of patients with COPD.

Considering patients with COPD and healthy adults, our study appears small. However, patients with severe scoliosis who are naïve to noninvasive ventilation are relatively uncommon; in fact, we were unable to find previous studies in the literature of patients with incipient respiratory failure with this condition. We might have enlarged our cohort by including, for example, patients with pulmonary fibrosis but we elected to confine the restrictive group to those with an extrapulmonary and non-neurological cause for respiratory failure in order to attain data that were as "clean" as possible.

A further limitation of our study is that measures of muscle bulk (for example, by mid-thigh computed tomography crosssectional area [1]) were not available. Thus, it cannot be 


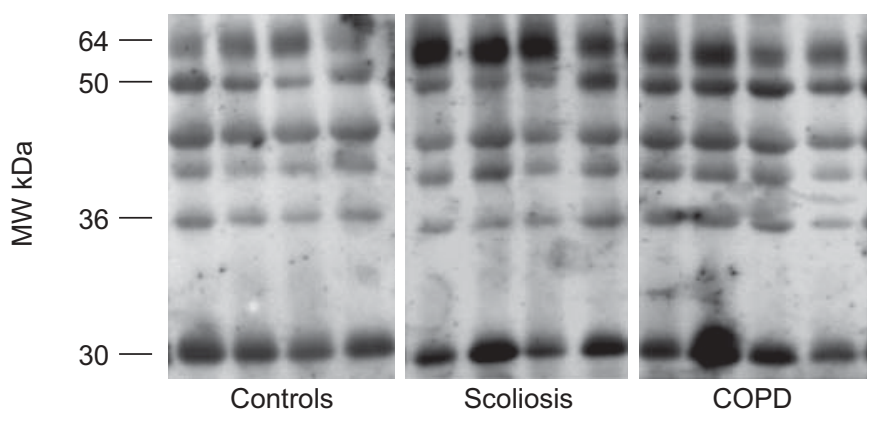

FIGURE 4. Representative examples of malondialdehyde (MDA)-protein adducts and glyceraldehyde-3-phosphate dehydrogenase in quadriceps of control subjects, severe scoliosis patients and chronic obstructive pulmonary disease (COPD) patients. Several MDA-protein adducts were detected. MW: molecular weight.

assumed that weakness is synonymous with atrophy, although most data, including a recent study from our group using ultrasound [21], suggest that muscle bulk is the primary determinant of strength [22]. Unfortunately, we did not have $6 \mathrm{MWT}$ data on our healthy control subjects; however, the expected 6MWT distance for our control group would be $574 \mathrm{~m} \mathrm{[23];} \mathrm{therefore,} \mathrm{both} \mathrm{patient} \mathrm{groups} \mathrm{may} \mathrm{be} \mathrm{considered}$ to have, as expected, a substantial and clinically relevant reduction in exercise capacity.

\section{Significance of the findings}

Our data demonstrate severe skeletal muscle weakness in patients with extrapulmonary restrictive lung disease, accompanied by a change in MyHC isoform expression. Although not directly measured, we assume weakness to be associated with muscle wasting, i.e. loss of muscle bulk [21]. Few data on this topic exist, although quadriceps weakness was also observed in the few restrictive patients who participated in a previous study investigating the effect of noninvasive mechanical ventilation [24]. In addition, if they complete the course, pulmonary rehabilitation is effective for such patients [3], consistent with our finding that quadriceps weakness is present.

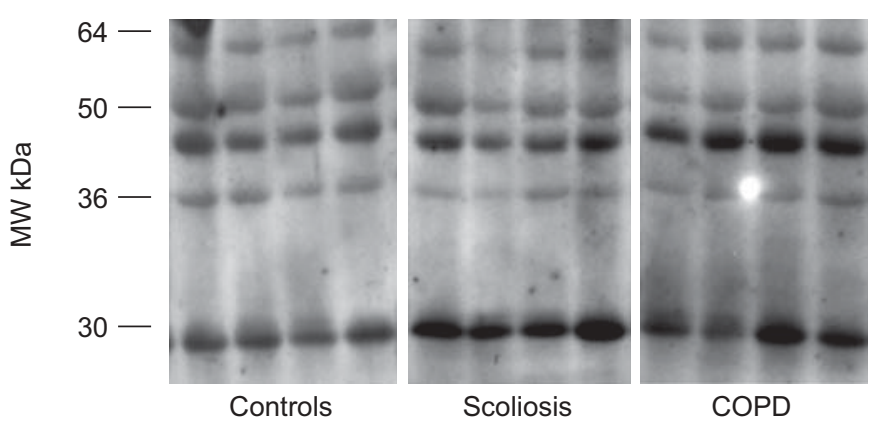

FIGURE 5. Representative examples of protein tyrosine nitration (total 3nitrotyrosine immunoreactivity) and glyceraldehyde-3-phosphate dehydrogenase in quadriceps of control subjects, severe scoliosis patients and chronic obstructive pulmonary (COPD) patients. Several tyrosine-nitrated proteins were detected. MW: molecular weight.
The Barcelona group [5] and other investigators [25, 26] have already argued that oxidative and nitrosative stress are increased in the muscles of patients with COPD. Indeed, oxidative stress has been proposed as one of the most important mechanisms involved in the aetiology of peripheral muscle dysfunction in COPD. In the current study, we again observed that lower limb muscles of patients with COPD undergo severe protein carbonylation and nitration. However, showing similar findings in the vastus lateralis of patients with scoliosis is an important development. Since these patients also had quadriceps weakness, our data suggest that both oxidative and nitrosative stress were also involved in the peripheral muscle dysfunction of the scoliosis patients, although it is acknowledged that our data do not demonstrate a causal role. Interestingly, when considering the entire dataset, a weak inverse relationship was observed between increasing protein tyrosine nitration and increasing muscle weakness (data not shown). MONTES DE OCA et al. [27] have recently reported evidence of increased nitric oxide end-products in smokers, but this cannot explain our observations in patients with restrictive disease as they were, in nine out of 10 instances, nonsmokers.

We believe the present study to be the first in which quadriceps biopsy has been undertaken in patients with Type II respiratory failure due to scoliosis; interestingly, however, quadriceps biopsy of patients with scoliosis who were not in respiratory failure was undertaken by MAFFULLI [28], who found "a mild dominance" of Type I fibres, in contrast with the current results. In the study by MAFFULLI [28], patients were referred for spinal surgery rather than because of suspected Type II respiratory failure and therefore disease severity or age may explain this discrepancy. A recent metaanalysis [29] has confirmed frequent prior observations [30-32] that Type II fibres predominate in patients with advanced COPD, an observation repeated in the present study. Our data show that, in patients with scoliosis, with a degree of weakness and respiratory impairment which equalled or exceeded that seen in patients with COPD myosin shifts in MyHC isoform expression also occur. Overall, the pattern in scoliosis patients resembled COPD patients, in that Type I MyHC isoform expression was reduced, but we note that the magnitude of the reduction was less than in COPD patients and that in scoliotics the "beneficiary" was Type IIx MyHC isoform expression, whereas in COPD, MyHC IIa was increased. The reason for this discrepancy is unclear and not clarified by the present data, but since MyHCIIx is viewed by some investigators as an adaptive response, one could speculate that this reflects the more profound strength loss and the longer history of preceding disease typically seen in scoliosis.

These data suggest that factors common to scoliosis and COPD are driving fibre-type shift. The pathophysiological mechanism remains to be elucidated and candidate mechanisms will need to be evaluated in future studies. One striking finding in the present study was the reduced BMI in the scoliotic patients; it has recently been noted elsewhere that BMI is disproportionately reduced in paediatric scoliotic patients with the most severe pulmonary restriction [33], although we acknowledge that the patients in that study were very much younger than our own. However, similar changes were observed in COPD patients who did not have a reduced BMI and it has also been 
established that the prevalence of quadriceps weakness in COPD exceeds that of fat-free mass depletion [34, 35]. Comparison with COPD, for which more data are available, suggests that reduced physical activity could also be a candidate mechanism, although this was not measured in the present study. Fibre-type changes are clinically relevant because they predispose, in a manner related to its severity, to leg discomfort and low-frequency fatigue during exercise [36]. Our data suggest that this mechanism could also be operative in scoliotics.

Factors that our COPD patients might have been exposed to, even though studied in a stable condition, include systemic inflammation, drugs (including corticosteroids) used to treat prior exacerbations, and associated comorbidities, such as peripheral vascular disease. These factors were not systematically evaluated in the present cohort, although no participants were using oral steroids when biopsied, or indeed for a minimum of 4 months beforehand. Corticosteroids are known to be associated with muscle atrophy through a myostatindependent mechanism [37] which increases expression of atrogenes, including atrogin and muscle ring finger protein 1. However, steroid-induced muscle atrophy usually preferentially involves Type II fibres, so this, coupled with the lack of recent exposure in our cohort, seems an unlikely mechanism. It has already been noted that systemic inflammation was not evaluated in the present study. Patients with COPD experience exacerbations to a greater extent than patients with scoliosis disease; quadriceps strength is decreased during exacerbation [38]. Data concerning the effect of exacerbation frequency on quadriceps strength and its relationship with loss of fat-free mass is presently sparse [35], but only two of our COPD patients had had exacerbations in the previous year, and none in the preceding 3 months. Lastly, hypoxaemia, at least at rest, seems an unlikely explanation of our findings since the median arterial oxygen tension in scoliotic patients was $9.1 \mathrm{kPa}$. However, we acknowledge that, like COPD patients, scoliotic patients develop exercise-induced hypoxia [39]; this was not measured in the present study and cannot be excluded as a potential trigger.

In conclusion, we provide the first data documenting the function and content of the quadriceps muscle in patients with advanced scoliosis and compare them with both COPD patients and healthy adults. Important similarities were weakness of the quadriceps muscle, reduced Type I myosin and the presence of oxidative stress, suggesting a common aetiological mechanism in both disease groups.

\section{SUPPORT STATEMENT}

This study was funded by an EU grant (QLK6-CT-2002-02285) entitled "European Network for Investigating the Global mechanisms of Muscle Abnormalities In COPD". The project was undertaken in part at the National Institute for Health Research (NIHR) Biomedical Research Unit in Advanced Lung Disease at the Royal Brompton and Harefield National Health Service (NHS) Foundation Trust and Imperial College London (London, UK). The views expressed in this publication are those of the authors and not necessarily those of the NHS, the NIHR or the Department of Health. Assistance was also provided by CIBERES (Instituto de Salud Carlos III, Ministerio de Ciencia e Innovación, Spain) and 2005-SGR01080 (AGAUR, Catalan Government, Spain). M.I. Polkey's salary is part funded by the Biomedical Research Unit. The research of H. Gosker is supported by a grant from the Netherlands Asthma Foundation (NAF 3.4.05.038). S.A. Sathyapala is supported by a Wellcome Fellowship Award (079686). E. Barreiro was a recipient of the European Respiratory Society COPD Research Award 2008.

\section{STATEMENT OF INTEREST}

Statements of interest for S.A. Sathyapala and M.I. Polkey can be found at www.erj.ersjournals.com $/ \mathrm{misc} /$ statements.dtl

\section{REFERENCES}

1 Marquis K, Debigare R, Lacasse $Y$, et al. Midthigh muscle crosssectional area is a better predictor of mortality than body mass index in patients with chronic obstructive pulmonary disease. Am J Respir Crit Care Med 2002; 166: 809-813.

2 Swallow EB, Reyes D, Hopkinson NS, et al. Quadriceps strength predicts mortality in patients with moderate to severe chronic obstructive pulmonary disease. Thorax 2007; 62: 115-120.

3 Naji NA, Connor MC, Donnelly SC, et al. Effectiveness of pulmonary rehabilitation in restrictive lung disease. J Cardiopulm Rehabil 2006; 26: 237-243.

4 Vogiatzis I, Terzis G, Nanas S, et al. Skeletal muscle adaptations to interval training in patients with advanced COPD. Chest 2005; 128 : 3838-3845.

5 Barreiro E, Gea J, Corominas JM, et al. Nitric oxide synthases and protein oxidation in the quadriceps femoris of patients with chronic obstructive pulmonary disease. Am J Respir Cell Mol Biol 2003; 29: 771-778.

6 Gosker H, Zeegers M, Wouters E, et al. Muscle fibre type shifting in the vastus lateralis of patients with COPD is associated with disease severity: a systematic review and meta-analysis. Thorax 2007; 62: 944-949.

7 Steiner MC, Barton RL, Singh SJ, et al. Bedside methods versus dual energy X-ray absorptiometry for body composition measurement in COPD. Eur Respir J 2002; 19: 626-631.

8 Linderholm H, Lindgren U. Prediction of spirometric values in patients with scoliosis. Acta Orthop Scand 1978; 49: 469-474.

9 Edwards RHT, Young A, Hosking GP, et al. Human skeletal muscle function: description of tests and normal values. Clin Sci 1977; 52: 283-290.

10 Swallow EB, Gosker HR, Ward KA, et al. A novel technique for nonvolitional assessment of quadriceps muscle endurance in humans. J Appl Physiol 2007; 103: 739-746.

11 Kufel TJ, Pineda LA, Mador MJ. Comparison of potentiated and unpotentiated twitches as an index of muscle fatigue. Muscle Nerve 2002; 25: 438-444.

12 Polkey MI, Kyroussis D, Hamnegard C-H, et al. Quadriceps strength and fatigue assessed by magnetic stimulation of the femoral nerve in man. Muscle Nerve 1996; 19: 549-555.

13 Mills GH, Kyroussis D, Hamnegard C-H, et al. Bilateral magnetic stimulation of the phrenic nerves from an anterolateral approach. Am J Respir Crit Care Med 1996; 154: 1099-1105.

14 Bergstrom L. Muscle electrolytes in man. Determination by neutron activation analysis on needle biopsy specimens. A study on normal subjects, kidney patients, and patients with chronic diarrhea. Scand J Clin Lab Invest 1962; 68: 1-110.

15 Gosker HR, Schrauwen P, Broekhuizen R, et al. Exercise training restores uncoupling protein-3 content in limb muscles of patients with chronic obstructive pulmonary disease. Am J Physiol Endocrinol Metab 2006; 290: E976-E981.

16 Barreiro E, Coronell C, Lavina B, et al. Aging, sex differences, and oxidative stress in human respiratory and limb muscles. Free Radic Biol Med 2006; 41: 797-809.

17 Barreiro E, de la Puente B, Minguella J, et al. Oxidative stress and respiratory muscle dysfunction in severe chronic obstructive pulmonary disease. Am J Respir Crit Care Med 2005 15, 171: 1116-1124. 
18 Koechlin C, Couillard A, Cristol JP, et al. Does systemic inflammation trigger local exercise-induced oxidative stress in COPD? Eur Respir J 2004; 23: 538-544.

19 Barreiro E, Schols AM, Polkey MI, et al. Cytokine profile in quadriceps muscles of patients with severe COPD. Thorax 2008; 63: 100-107.

20 Crul T, Spruit MA, Gayan-Ramirez G, et al. Markers of inflammation and disuse in vastus lateralis of chronic obstructive pulmonary disease patients. Eur J Clin Invest 2007; 37: 897-904.

21 Seymour JM, Ward K, Sidhu P, et al. Ultrasound measurement of rectus femoris cross-sectional area and the relationship to quadriceps strength in chronic obstructive pulmonary disease. Thorax 2009; 64: 418-423.

22 Suetta C, Aagaard P, Magnusson SP, et al. Muscle size, neuromuscular activation, and rapid force characteristics in elderly men and women: effects of unilateral long-term disuse due to hip-osteoarthritis. J Appl Physiol 2007; 102: 942-948.

23 Enright PL, Sherrill DL. Reference equations for the six-minute walk in healthy adults. Am J Respir Crit Care Med 1998; 158: 1384-1387.

24 Schonhofer B, Zimmermann C, Abramek P, et al. Non-invasive mechanical ventilation improves walking distance but not quadriceps strength in chronic respiratory failure. Respir Med 2003; 97: 818-824.

25 Couillard A, Maltais F, Saey D, et al. Exercise-induced quadriceps oxidative stress and peripheral muscle dysfunction in patients with chronic obstructive pulmonary disease. Am J Respir Crit Care Med 2003; 167: 1664-1669.

26 Koechlin C, Couillard A, Simar D, et al. Does oxidative stress alter quadriceps endurance in chronic obstructive pulmonary disease? Am J Respir Crit Care Med 2004; 169: 1022-1027.

27 Montes de Oca M, Loeb E, Torres SH, et al. Peripheral muscle alterations in non-COPD smokers. Chest 2008; 133: 13-18.

28 Maffulli N. Histochemical and physiological studies in idiopathic scoliosis. Ital J Orthop Traumatol 1990; 16: 61-71.
29 Gosker HR, Zeegers MP, Wouters EF, et al. Muscle fibre type shifting in the vastus lateralis of patients with COPD is associated with disease severity: a systematic review and meta-analysis. Thorax 2007; 62: 944-949.

30 Jakobsson P, Jorfeldt L, Brundin A. Skeletal muscle metabolites and fibre types in patients with advanced chronic obstructive pulmonary disease, with and without chronic respiratory failure. Eur Respir J 1990; 3: 192-196.

31 Jakobsson P, Jorfeldt L, Hanriksson J. Metabolic enzyme activity in the quadriceps femoris muscle in patients with severe chronic obstructive pulmonary disease. Am J Respir Crit Care Med 1995; 151: 374-377.

32 Maltais F, Simard AA, Simard C, et al. Oxidative capacity of the skeletal muscle and lactic acid kinetics during exercise in normal subjects and in patients with COPD. Am J Respir Crit Care Med 1996; 153: 288-293.

33 Bowen RE, Scaduto AA, Banuelos S. Decreased body mass index and restrictive lung disease in congenital thoracic scoliosis. J Pediatr Orthop 2008; 28: 665-668.

34 Franssen FM, Broekhuizen R, Janssen PP, et al. Limb muscle dysfunction in COPD: effects of muscle wasting and exercise training. Med Sci Sports Exerc 2005; 37: 2-9.

35 Hopkinson NS, Tennant RC, Dayer MJ, et al. A prospective study of decline in fat free mass and skeletal muscle strength in chronic obstructive pulmonary disease. Respir Res 2007; 8: 25.

36 Saey D, Michaud A, Couillard A, et al. Contractile fatigue, muscle morphometry, and blood lactate in chronic obstructive pulmonary disease. Am J Respir Crit Care Med 2005; 171: 1109-1115.

37 Gilson H, Schakman O, Combaret L, et al. Myostatin gene deletion prevents glucocorticoid-induced muscle atrophy. Endocrinology 2007; 148: 452-460.

38 Spruit MA, Gosselink R, Troosters T, et al. Muscle force during an acute exacerbation in hospitalised patients with COPD and its relationship with CXCL8 and IGF-I. Thorax 2003; 58: 752-756.

39 Meecham Jones DJ, Paul EA, Bell JH, et al. Ambulatory oxygen therapy in stable kyphoscoliosis. Eur Respir J 1995; 8: 819-823. 